\title{
Examining Women's Role in Conflict Resolution in Alamata Town, Ethiopia
}

\author{
Alexander Haymanot Abrha \\ Lecturer, Department of Civic and Ethical Studies, College of Social Sciences and Humanities, Raya University, \\ P.O. Box 92, Maychew, Ethiopia
}

\begin{abstract}
The main objective of this study was to examine women's role in conflict resolution in Alamata Town, Ethiopia. As women can have an important role in a country's peace talks and conflict resolution, their involvement is much needed in order to lead Ethiopia forward. However, today, the role of women in conflict resolution is underappreciated and is still being undermined by traditionally male dominated political and socio-economic structure in Ethiopia in general, specifically in Alamata Town. Hence, one may ask whether women have been participated in conflict resolution to their full potential in the study area. The study therefore sought to examine the roles of women in conflict resolution in Alamata Town. In this study, qualitative research method was used. This study was conducted based on a descriptive research design. The target populations of this study were the women households who were working in conflict resolution in the study area. The study sampled 20 women households' respondents selected through purposive sampling technique in the study area. The researcher employed both primary and secondary sources of data and the data was collected using focus group discussion and personal observation. The qualitatively data was analyzed and interpreted using content analysis. The study found out that women were actually involved, though not enough, in peace initiatives or conflict resolution situations in the Town. The study concluded that despite many challenges women faced, they were able to contribute significantly to conflict resolution activities in the study area. This paper therefore, recommended that gender sensitivity (perspectives) and inclusion need to be mainstreamed in all policy processes to assure and continue the productive involvement of women in resolving conflicts.
\end{abstract}

Keywords: Examining, Women, Roles, Conflict, Resolution, Alamata, Ethiopia

DOI: 10.7176/RHSS/9-17-06

Publication date:September $30^{\text {th }} 2019$

\section{Introduction}

\subsection{Background of the Study}

Throughout history women have been part of peace building and war-making. Yet when it comes to formal negotiation processes and to decision-making processes, they have been largely ignored. As was mentioned before, women have been excluded from most decision-making processes. This discriminatory tendency started to be reversed in 1949, with "The Convention Relative to the Treatment of Prisoners of War..." the "first modern-day international instrument to establish protections against rape for women" (Murray, 2011).

However, discrimination, rape, and lack of protection continued. Because of this, women's groups and civil society continued to push to put an end to discrimination. As a result, the convention for Elimination of All Forms of Discrimination against Women (CEDAW Convention) was created in 1976. The convention advocated for the need to end discrimination towards women. It was signed and ratified by 189 countries (Simonov, 2010).

The CEDAW was a major legal step towards ending women's discrimination. Discrimination tendencies persisted and women groups and civil society continued to advocate for their rights. This led the international community to establish the Beijing Platform for Action (BPA) in 1996. The BPA identified strategic priorities and created necessary actions and strategies to move forward when it came to women's discrimination (ibid).

Yet, women continued to be segregated. This was especially evident when it came to peace processes where women are almost completely ignored. Attempting to fill this gap the United Nations Security Council established Resolution 1325 in the year 2000 (United Nations Security Council, 2000).

Resolution 1325 was very significant because it recognized the importance of including women in peace building processes and all decision-making processes. "The inclusion of women is rooted in the premise that their presence, participation and perspectives will improve the chances of attaining viable and sustainable peace. It is also based on the knowledge that if half the population faces discrimination and violence there can be no peace" (GAPS, 2010).

A report performed by Judy El-Bushra, with the organization International Alert confirms the importance of the resolution: "Activists stress the importance and variety of women's roles in peace building and the need to support women's peace organizations. UNSC Resolution 1325 echoes this concern, and represents a global policy commitment to support women's role in peace building and in post-conflict reconstruction. Resolution 1325 is seen as a tool to promote women's empowerment, as well as a basis for mobilizing women as a resource to render peace processes more effective" (El-Bushra, 2012). 
In the recent past, countries in Africa have had numerous conflicts and presently the problem is far from being abated. This has caused untold suffering on the people and also taken a huge toll on the development of the continent. The horn of Africa, particularly the Great Lakes regions, have become locations for some of the deadliest and most protracted of these conflicts. In 2006 alone, there were 17 conflicts in Africa, which were at varying degrees of forms and intensity. Of all the countries in the Greater Horn of Africa only two (Djibouti and Tanzania) can be said to be relatively stable, although each has its fair share of internal skirmishes. Kenya was also stable until the post-election crisis erupted (Mpangala, 2004).

In the African context, women have played a major role in the peace building processes in post conflict situations. For example, after the Rwandan genocide of 1994, Eloise Inyumba, the social affairs minister, led women into burying the dead, finding homes for the orphaned and resettling refugees. She also served as the executive secretary of the National Unity and Reconciliation Commission which organized public debates promoting reconciliation between the Hutus and Tutsis (Anderlini, 2007).

In Somalia, women poets use their art to preach peace and peaceful co-existence among bordering communities. The major aim of the poets is to encourage reconciliation, instill peace and unity among bordering communities despite the rapid conflict in the areas. In Namibia, spiritual healing rituals were done by women to purify and cleanse the war returnees of blood guilt. This was to ensure that the desire to kill did not spread. In Kenya, resource based conflicts specifically involving water in arid and semi-arid areas have been common. Many of the conflicts revolve around livestock, need for water and harsh climatic conditions (Becker, 2003).

In Ethiopia the place of women in conflict resolution has however not been adequately studied. This is due to the socio-cultural set up in the Ethiopian communities where the patriarchal systems have dominated both the formal and informal sectors. This study contributes in the expanding of literature on the role of women in conflict resolution in reference to Alamata Town. Alamata Town has been identified as the areas of study because little has been done on the women's role in conflict resolution. Therefore, there is need to examine women's role in conflict resolution in the study area.

\subsection{Statement of the problem}

Ethiopian women have traditionally been excluded from the public sphere, but have recently emerged as a political and social force, as their participation in civic and political arenas is increasing. Most importantly, their participation is crucial for further development of the country and achieving stability in national security. However, women still face vast challenges, in the form of violence, security threats, lack of education and employment opportunities, which are limiting their opportunities in life. Women's participation is important for implementing development projects and resolving conflicts in a better way. As women can have an important role in a country's peace talks and conflict resolution (UNSC, 2000), women's support is needed in order to lead Ethiopia forward.

However, women have been discriminated against and under-represented in the traditionally maledominated political and socio-economic structure in Ethiopia. The inequalities are prevalent in most male dominated societies around the country. Alamata Town is not exceptional. This is because the role of Women in Conflict resolution is underappreciated and is still being undermined by male dominated societies in the study area. In Alamata Town, these disadvantages made it difficult for women to play their roles in conflict resolution. Today, women continue to be excluded and segregated, and the country continues to be in crises. As per the researcher's observation, to protect women in conflict situations and address the imbalances between men and women in conflict situations, no research was conducted in the study area. The study therefore sought to examine roles of women in conflict resolution in Alamata Town.

\subsection{Objectives of the study}

\subsubsection{General objectives of the study}

The general objective of the study was to examine the role of women in conflict resolution in Alamata Town.

\subsubsection{Specific objectives of the study}

1. To investigate what roles the women in Alamata Town play in conflict resolution

2. To identify what strategies the women of Alamata Town adopt in resolving the conflicts occurred among the communities

3. To evaluate the factors that hinder the participation of women in conflict resolution in the study area

4. To investigate what can be done to enhance women's participation in conflict resolution

\subsection{Research questions}

1. What is the role of women in conflict resolution in Alamata Town?

2. What are the coping mechanisms that women of Alamata Town adopt in resolving the conflicts occurred among the communities? 
3. What are the factors that hinder the participation of women in conflict resolution in the study area?

4. What can be done to enhance women's participation in conflict resolution?

\section{Literature Review}

\subsection{Theoretical Framework}

This study was guided by Conflict Theory and Social Feminist Theory.

\subsubsection{Conflict Theory}

According to Murray (2011) conflict theory suggests that human behavior in social contexts results from conflicts between competing groups. Conflict theory originated with the work of Karl Marx in the mid-1800s. This thinking also inspired Max Weber who agreed in the importance of wealth but argued that power and status were of equal importance. Both saw different groups in conflict over social scarcities.

Conflict theory emphasizes the role that a person or groups has to exercise to control others in producing social order. It states that a society or organization functions so that each individual participant and its groups struggle to maximize their benefits, which inevitably contributes to social change such as changes in politics and revolutions. The struggle that occurs does not always involve physical violence; it can point to an underlying struggle for each group or individual within a society to maximize its own benefits (Becker.2003).

The essence of conflict theory is best epitomized by the classic 'pyramid structure' in which an elite dictates terms to the larger masses. All major institutions, laws, and traditions in the society are created to support those who have traditionally been in power, or the groups that are perceived to be superior in the society according to this theory. In summary, conflict theory seeks to catalogue the ways in which those in power seek to stay in power. The conflict theory basically states that all problems are caused by different groups and their status and how they compete for the necessities in life (Colin, 2006).

Conflict theory seeks to scientifically explain the general contours of conflict in society: how conflict starts and varies, and the effects it brings. The central concerns of conflict theory are the unequal distribution of scarce resources and power which gives some people leverage than others. The theory major argument is that the unequal distribution of resources is determined by culture, norms and belief in any society. Hence, this theory was used here to shed light on how social factor and economic factors have impacted on the participation of women in conflict resolution efforts in Alamata Town.

\subsubsection{Social Feminist Theory}

The concepts of the study are mainly based on the feminist theory and which attempt to improve the role of women in conflict resolution activities. This study will be guided by the social feminist ideology. Butler (2009), contend that social feminists recognized that the exploitations, discrimination, marginalization and oppression of women are deeply rooted in the social structures such as patriarchal capitalism. In most peace building initiatives, men are ironically presented as "people" or the "doers while women are seen as "others, passive or innocent victims." The social feminists believe that gender based discrimination is so deeply seated in the social relationships of patriarchal capitalism that a fundamental transformation is necessary to bring about social transformation (in this case, gender equality). Given that women constitute half the population in post-conflict societies, then, there is need to include women in peace building efforts, policy and decision-making process if sustainable peace building is anything to go by. The theoretical framework for the present research thus adopted the feminist ideology in an attempt to explore the factors that influence women's participation in conflict resolution in Alamata Town.

\subsection{Conflict and Conflict Resolution}

Conflict means disagreement that arises due to differences that can result from divergences of interests in a society. Conflict is caused when two or more parties perceive that their interests are incompatible, and want to achieve their aims through actions that damage the interest of the other. These parties may be individuals, small or large groups or countries (Munro Jean, 2000).

Conflict resolution is seen by Miller (2003) as a variety of approaches aimed at terminating conflicts through the constructive solving of problems, distinct from management or transformation of conflicts. Miller indicate that by conflict resolution, it is expected that the deep rooted sources of conflict are addressed and resolved, and behavior is no longer violent, nor are attitudes hostile any longer, while the structure of the conflict has been changed. Mitchel and Banks (2009) refer to conflict resolution as:

i. An outcome in which the issue in an existing conflict are satisfactorily dealt with a solution that is mutually acceptable to the parties, self-sustaining in the long run and productive of a new, positive relationship between parties that were previously hostile adversaries; and

ii. Any process or procedure by which such an outcome is achieved.

The way in which gender is integral to peace, and violent conflict makes clear that a gendered analysis of peace building is essential to preventing and mitigating new violent conflict in societies while helping them recover from current conflicts. 


\subsection{Women and their roles in conflict resolution}

Throughout history women have been seen as passive actors of war and peace. Either they have nothing to do with war or they are victims of it. This idea is embedded in most societies, as could be seen in a conference held in the Wilson Center in January 2013 (Wilson Center, 2013). During the conference Marta Ruiz, a well-known Colombian journalist, was asked to give her opinion on the fact that there were no women in the Colombian Peace Process. To this she answered "la Guerra es una cosa de hombres, ha sido una cosa muy masculina y que las mujeres han tenido un papel muy marginal realmente en la Guerra" (War is a men's thing. It is very masculine and women play a marginal role in it) (Wilson Center, 2013).

As was stated before, Marta Ruiz is not the only person to believe this. According to a research that is being performed by the Institute of Collaborative Learning Projects "Many people assume that since women bear children and are their primary caregivers, they are predisposed to be peaceful and reject violence. In reality, neither sex nor gender roles are predictors of peacefulness" (Brewing, 2012).

In her doctoral thesis research Mary McCarthy stated that while women are generally the victims during conflict, their condition should not be misconstrued as one of passivity. Because of the extreme circumstances in which they are placed, women often adopted proactive strategies to ensure their survival and to provide for their families. Further, women do not always retain their civilian status during these wars they are increasingly likely to participate either as combatants or as women associated with fighting forces (WAFF), who provide logistical and economic support for the fighters (McCarthy, 2011).

International Alert also confirms this belief: "globally, men do predominate not only as actors in war but also as perpetrators of violence, practitioners of extreme physical feats, and decision-makers in institutions that underpin violence. Women (with some exceptions) are less commonly engaged directly in combat or violence, yet they support violence in many indirect ways, e.g. by providing services to fighters, through the way they educate their children, and by encouraging men to engage in violence. As such they may be key players in the creation of "murderous ideologies." A review of data from different parts of the world and different historical periods shows that both men and women can be both victims and perpetrators of violence, and both men and women can exert extraordinary efforts, overcoming fearful odds, for peace" (El-Bushra 2012).

According to the United States Institute for Peace throughout the last century women are becoming more and more directly involved in armed conflict: "Over the past century, the nature of armed conflicts has changed. In particular, wars are no longer primarily interstate conflicts arising out of national interests This reconfiguration has been accompanied by the increased awareness that women are no longer if they ever were simply civilians standing on the sidelines or camp followers trudging along (or lying beneath) the soldiers. As Charlotte Lindsey has observed, "The assumption that women are vulnerable overlook the fact that women are more and more frequently taking up arms" (Theydon et al., 2011).

Women therefore do have a lot to do with war. They can be victims, perpetrators, war-resisters, supporters of violence, and peacemakers. Sometimes these roles overlap and women end up playing all roles at the same time. It is important to note regardless of all the roles women play in conflict they should be a part of the peace process because "in addition to the potential for women to contribute to successful peace outcomes, their participation should also be encouraged on the basis of fairness and justice" (McCarthy 2011, 30). Women account for more than $50 \%$ of the world's population and a successful peace process cannot ignore more than half of the population.

\subsection{The causes of conflict}

Conflict in Ethiopia is often the result of both natural and social factors. Its consequences, meanwhile, can be as minor as marital and domestic dispute; or as major as armed struggle. In simplistic form, the different types of conflict and their consequences can be categorized as follows:

Scant natural resource: One of the major causes of conflicts, especially in the pastoral areas of Ethiopia, is access to the use of scarce natural resources such as water and pasture for livestock. Increased by drought, flood and famine, the lack of natural resources leads to ethnic conflicts; rivalry over grazing land, water and fishing resources; environmental degradation and over cultivation; and, typically amongst pastoralist communities, cattle raiding. Women are primary victims in these types of conflict since they are responsible of fetching water, collecting firewood and care for livestock (Habtamu, 2008).

Culture of conflict: The other major cause of conflict is related to the cultural practices of various community and ethnic groups who feel superior to other groups or communities. Cattle rustling, forced marriages from other tribes, encouraging younger boys to prove good warriors and excessive dowry demands are among the causes perceived (ibid).

Inter-ethnic conflict: Primarily the result of the ethnic supremacy, migration, resettlement and internal and external displacement, ethnic conflict typically translates into; rivalry over resources and land, the isolation of certain groups, "favoritism" amongst ethnic groups, nepotism, and the unfair distribution of resources(ibid).

Gender related conflict: Often the result of perceived male superiority, gender-conflict results in violence 
against women. Such as wife beating, forced marriage, abduction, marital abuse, rape and unwanted pregnancies. These may result in physical damage to women and may eventually end with divorce (ibid).

Conflicting religious perceptions: Resulting from the simultaneous existence of different belief systems and forms of worship; traditional faiths, Islam and Christianity, ideological differences often lead to misunderstanding, lack of communication, and the erosion of the proven cultural traditions, which normally keep the different communities together (ibid).

Cross border conflicts: These are conflicts between two countries that share common boundaries. They may be caused by a combination of all of the above, or be triggered by instances of cattle raiding across borders. Dispute created between tribes that live on either side of borders or share resources between two countries, like lakes or rivers. Political instability typically results in the breakdown of the economy and the resulting poverty may cause conflict (ibid).

\subsection{Factors affecting women's participation of in conflict resolution}

\subsubsection{Social Factors influencing participation of women in conflict resolution}

Patriarchal norms are one of the major obstacles to women participation in conflict resolution strategies. They encourage the domination of women by men and create hierarchical structures where people are ranked not only according to gender, ethnicity, age, education, and sexual orientation, but also according to their conformity to patriarchal norms (Ekvall, 2015). As a result of patriarchal norms, men have continued to dominate the political and economic structures of power.

Women have been confined and prevented from participating in public life, in conformity with dictates of tradition, culture and religion. This also extends to conflict resolution processes. This is because most conflict resolution processes occur far away from original abode of the women and sometimes last for weeks or even months. The peculiar function of women as mothers and home managers further jeopardize their involvement in conflict resolution and peace building process, as their reproductive role is used to undermine their productive roles. Women's reconciliatory activities beginning from home manifests in conflict resolution at both the family and societal levels(ibid).

There are stereotypical assumptions about women's appropriate roles in society, particularly, decision making and their areas of expertise. Women are perceived as passive victims, who cannot contain the stress that is experienced in conflict resolution. There are usually doubts about whether they can endure the rules of engagement for achieving peace during conflict situations. This is because mediation is seen as a maledominated area due to the sometimes dangerous occurrences during the peace process that make safety and security an issue. In mediating and participating in conflict resolution processes, people become targets of perpetrators of conflicts. Some participants are threatened during negotiations. People's homes are bombed, and their relatives could be jailed or killed or simply uncertain of whether or not they will live to see the next day (Brownell, 2011). These risks can deter women from participating in conflict resolution at levels they would have preferred to.

Lastly, during conflict resolution processes, the neutrality of women as peace brokers comes into question. Warring parties tend not to take women's advocacy programs seriously because they are labeled as affiliates to the enemy. Also, the different factions tend to see women more as wives than as full parties to the negotiations (Lavalie, 2011). In some of these cases, women have to expend a lot of energy to prove that they are pursuing a common goal, one which cuts across the fault lines ethnic, religious, cultural and political, so that the warring parties agree to ceasefire and peaceful resolution of the conflict through dialogue.

\subsubsection{Skills Factors influencing participation of women in conflict resolution}

Women with the required conflict resolution knowledge and skills participate more than those without knowledge in conflict resolution efforts. This is espoused in UNSCR 1325 that envision a world where the contribution of women could be experienced in peace building efforts as guided by the skill of women in such process. This is an argument advanced by Agbalajobi (2010) who asserts that the ECOWARN system of ECOWAS conflict resolution architecture in West Africa is mainly male dominated due to women's lack of skills and know-how in the area. Rielly (2013) argues that this has affected the contribution of women to conflict resolution and thus will only change if women in both conflict and non-conflict settings are equipped with knowledge and skills in peace processes.

Moran (2010) found out that for women to participate in conflict resolution that support their education and literacy, as well as that tackle the barriers to girls' education can be important. These must, however, be accompanied by work with both men and women to raise awareness of the important insight that women's experiences of conflict, regardless of their level of education, can bring to peace and reconstruction planning.

\subsubsection{Economic Factors influencing participation of women in conflict resolution}

Conflicts leave societies destroyed and dilapidated and post-conflict recovery requires a huge financial base and resources. Such conflicts are destructive to the economies of different communities, with women among the most affected (Gibing, 2011) 
Due to poverty and economic inequality women lack control over their household income, therefore, they undertake a double burden regarding their domestic roles and income-generation activities and this hinders women's involvement in conflict resolution activities.

Poverty, and necessary prioritizing of income-generating activities, often a ,double burden “e for women, is viewed as not only inhibiting involvement in conflict resolution but also the achievement of peace in families and communities The lack of adequate, targeted funding for conflict resolution efforts is also a major economic barrier that has limited the participation of women at national and local levels (ibid).

Most women lack access to financial resources (USIP, 2011). More women in the developing world work in the informal sector and their wages and earnings are significantly lower than earnings of men. It is estimated that women's earnings are 20 percent lower than men (UNICEF, 2006). In general, women control fewer assets and often have little say in the allocation of household incomes. In informal household settings in Ghana, for instance, incomes from farm products are virtually controlled by men. Where women engage in their own businesses or work in the formal sector, in some cases, their earnings are controlled by men. This leads to economic dependence of these women. Their dependence on men limits their roles in conflict resolution.

\section{Research Methodology}

In this study, qualitative research method was used. Qualitative research methodology is designed to help researchers understand people's attitudes, experiences and feelings about what is being studied. This study was conducted based on a descriptive research design which helps the researcher to describe facts associated with the current situation of the role of women in conflict resolution in the case of Alamata Town.

In this study, both primary and secondary sources of data were used in order to obtain ample information so as to realize the objectives of this study. The primary data are those which are collected afresh and for the first time, and thus happen to be original in character. Primary data or first-hand information for this study was collected from research participants through FGD and personal observation. The data that was obtained from primary sources was supported by the secondary sources. The secondary data, on the other hand, are those which have already been collected by someone else and have been passed through the statistical process. Secondary data has been collected from books, journal articles as well as websites.

The target populations of this study were the women households who were working in conflict resolution in the study area. The researcher used purposive sampling technique because it enables the researcher to select those who are more familiar with the subject matter, thus they could provide the accurate information that will be relevant to the researcher's focus. Finally, the researcher selected 20 of the women households (FGD participants) who were working in conflict resolution activities in the study area.

In this study, FGD and personal observation data collection instruments were used. The focus group discussion is defined as bringing together a group of selected samples and it is a means to gather in-depth, qualitative data. Moreover, it is also a group discussion in which individuals are selected and assembled by the researcher to discuss and comment on topics that are identified by the researcher to draw upon respondents' attitudes, feelings, beliefs, experiences and reactions. The focus people are experts and community members, who were selected by using the purposive sampling technique.

Personal observation was also one method of data collection by which the researcher used to gain qualitative data by participating in the daily lives of those who are being studied. This method is close to every day interaction, involving conversations to discover understandings of the community in the study area.

Finally, after the data collected by FGD and observation, the collected data was organized in to homogeneous categories and then analyzed and interpreted qualitatively by describing and explaining through words. 


\section{Discussion and Results}

\subsection{The Background Characteristics of Respondents}

Figure 1: percentage distribution of respondent's sex in the study area

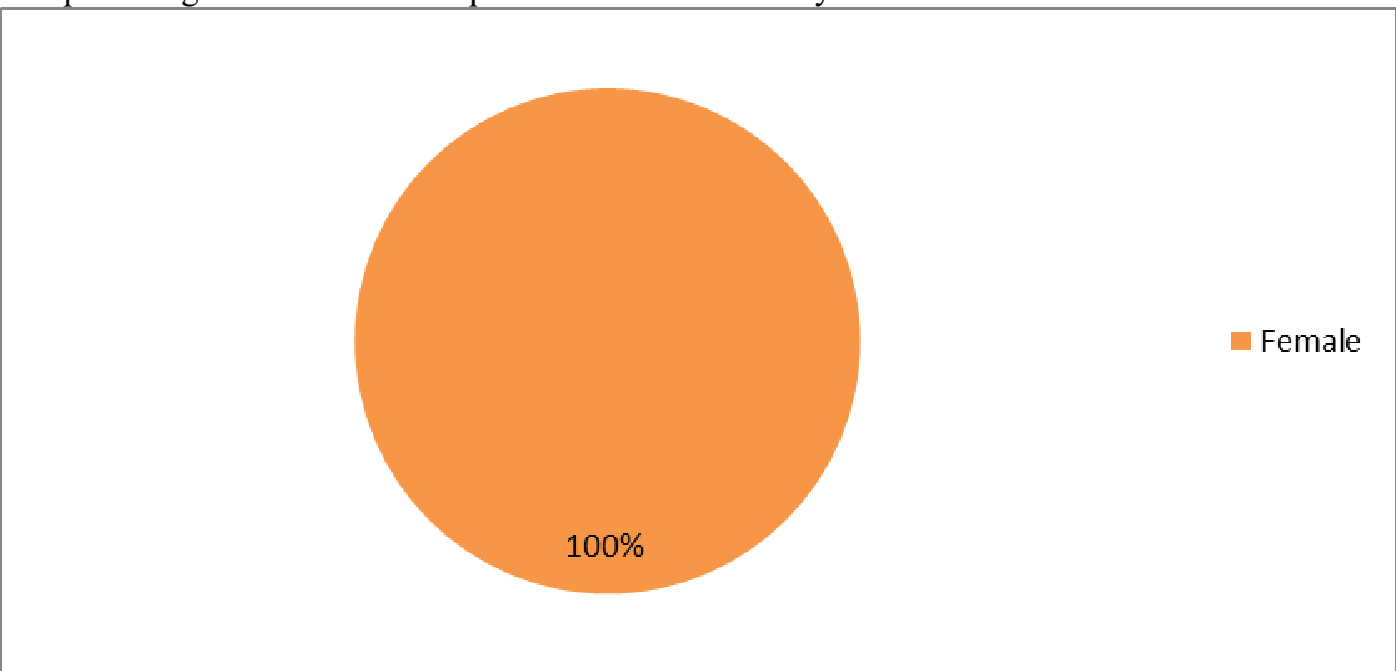

With respect to sex categories of the respondents, as indicated in the pie chart above, $100 \%$ of the respondents constitute females.

Figure 2: Frequency and percentage distribution of respondent's age in the study area

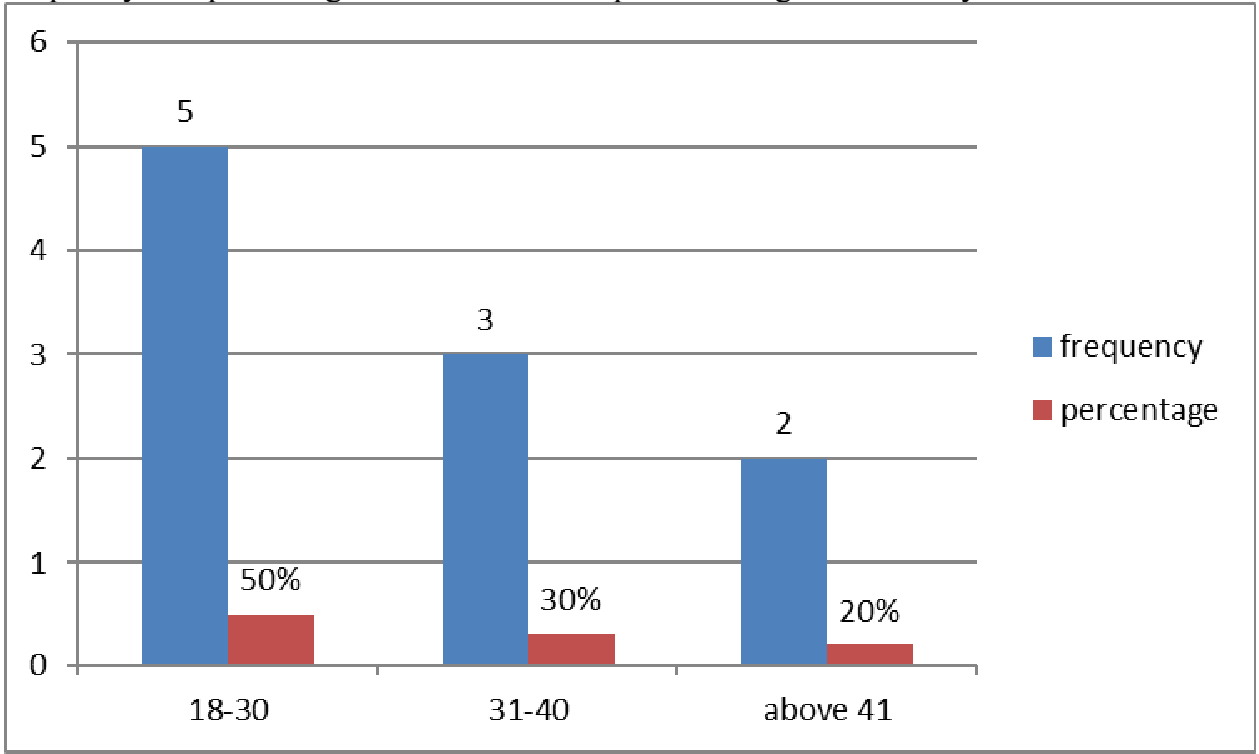

Data were also collected to describe age categories of the respondents. As indicated in the bar chart here above, the result shows that while $5(50 \%)$ of the respondents found in the age caterories of $18-30,3(30 \%)$ were found in the age group of $31-40$ and the remaining $2(20 \%)$ of the women respondents were found in the age caterories of above 41 . 
Figure 3: Frequency and percentage distribution of respondent's educational levels in the study area

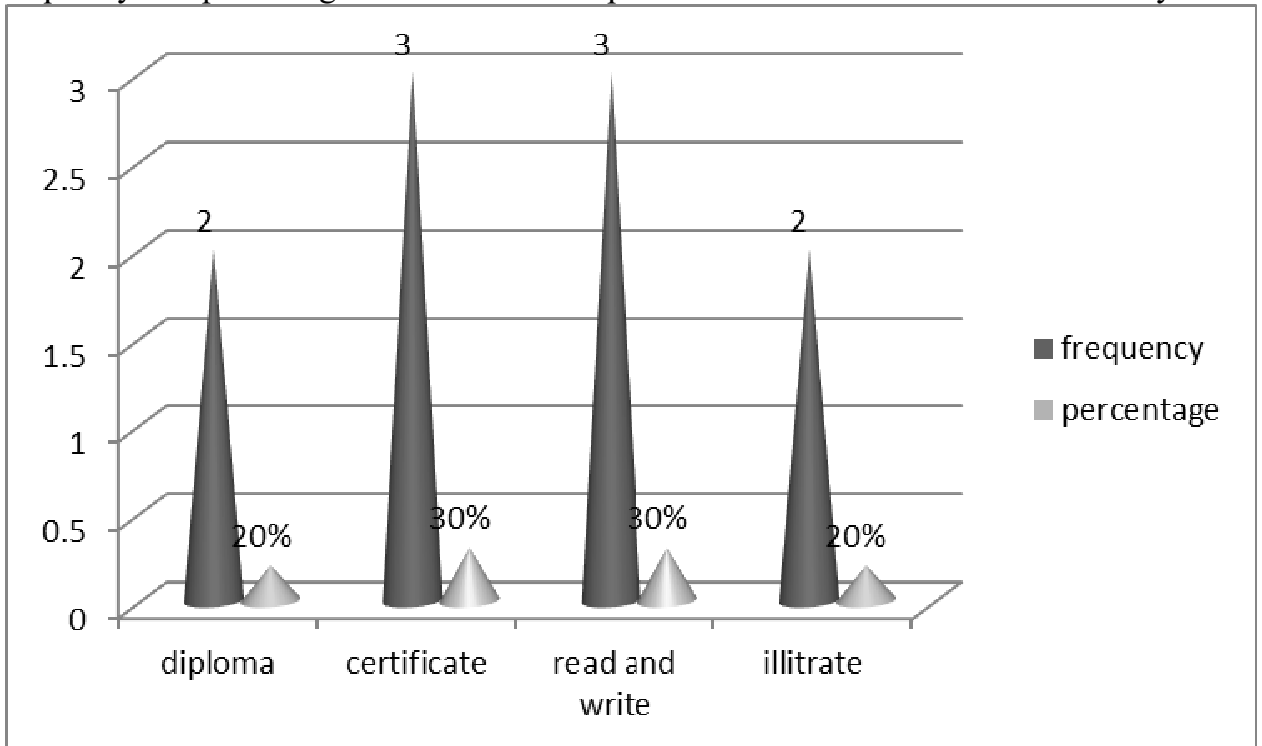

Demographic data were also collected to understand the educational levels of the respondents. So, as it is shown in the bar chart above $20 \%$ of the respondents were found to have diploma and $30 \%$ of them have certificate. The remaining $30 \%$ can read and write while $20 \%$ are illiterate.

Figure 4: Marital status of the Respondents.

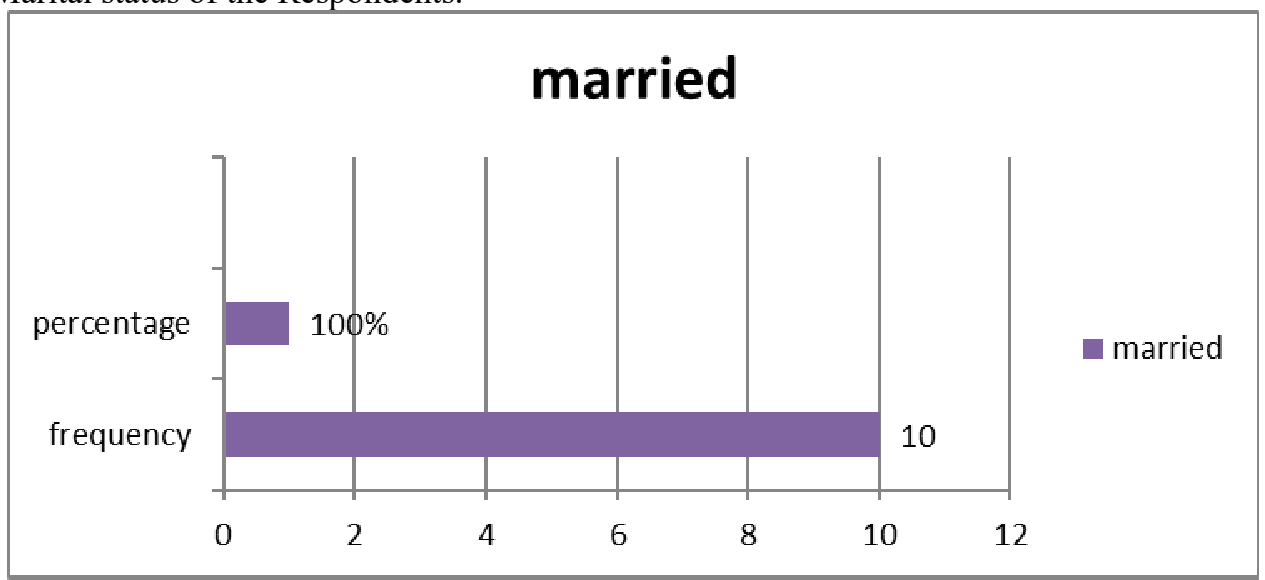

Regarding to the marital status, as shown above $100 \%$ of the women respondents was married.

\subsection{Qualitative Data Analyses}

\subsubsection{The role of women in conflict resolution}

The FGD participants were asked to state the role of women in conflict resolution in Alamata Town. Accordingly, most of the respondents responded that women have played their role in conflict resolution activities in their own residential area on a voluntary basis. The participants of the study also suggested that the women have attempted to maintain their own peace and security through neighborhood-watch programs, together with the police, which is an excellent sign of women role in crime prevention and conflict resolution initiatives though it was not that much enough.

Hence, according to the FGD participants, the women in Alamata Town have played the following roles:

$\checkmark$ Monitoring crime related activities;

$\checkmark$ Evaluating the day to day actions of the residents especially the suspected individuals;

$\checkmark$ Taking initiative to consult the community on their own safety and security issues;

$\checkmark$ Participating voluntarily in conflict resolution initiatives;

In addition, the researcher observed that since conflict is a societal problem, the women have a great role and responsibility for its resolution. Women are playing a leading role in conflict resolution issues. As the researcher, the possible roles of the women are:

However, some of the respondents mentioned that the women in Alamata Town didn't played the expected role in conflict resolution activities because of the socio-economic problems and lack of incentives which made the women not to play the role expected of them. In addition, they stated that the women were not willing to 
involve in conflict resolution rather they have left everything to the police.

\subsubsection{The level of women's participation in conflict resolution}

The FGD participants were asked to rate the level of women's participation in conflict resolution. Therefore, majority of the research participants have rated the levels of women's participation in conflict resolution in Alamata Town as high. The FGD participants mentioned that women were active in organizing and participating in community bases organizations in order to resolve conflicts occurred within the community in the study area. They added that women also play a key role in peace-building. They are activists for peace, and advocate for the end of violence; "women are among the first to speak out collectively against conflicts and to try to prevent escalation. That is evident locally in the Town. Moreover, more women from the town were involved in curbing the conflict from the kebele levels. They offered their lives and skills to make peace a lasting solution to the conflict.

According to the FGD participants, conflicts should be handled peacefully through mechanisms that accommodate competing interests. They added that conflict arises due to divergences of interests in the given society. These respondents strongly believed that conflict resolution is directed at understanding conflict processes and alternative non-violent methods that help disputing parties reach mutually acceptable positions that resolve their differences. Hence, women played a significant role to resolve conflicts before the conflict turns into violence using mediation which tries to help the disputing parties reach a mutually agreeable solution. In addition, women are working together on common problems to resolve conflicts peacefully. For example, where there is a conflict on drinking water, the people from both sides can come together and discuss how to get another water resource or arrange a program. Furthermore, the women are participating in identifying the commonly shared values, interests and goals which are quite useful to bring about consensus and create stability. These can be done through encouraging communication among different conflicting groups. The FGD participants clearly stated that women's roles in resolving the conflict in the town became more noticeable with the formation of community based associations through which they mobilized and galvanized the society (women in particular) to call for peace, democracy, and an end to hostilities.

The researcher also observed that women are participating in order to protect the basic individual rights by requiring the government to act in accordance with pre-announced, clear and general rules that are enforced by impartial courts in accordance with fair procedures. The researcher added that when these fundamental principles of the Constitution are respected, conflicts will be minimized easily and peace and security can be maintained.

On the contrary, $10 \%$ of the FGD participants strongly argued that women are excluded from principal roles in conflict resolution in the town. Though their roles were crucial to changing the landscape of the conflict, women have been subjected to widespread violence and poverty. These situations were the result of cultural norms developed over the years in a male dominated political and socio-economic national history. These respondents believed that policies are not designed to promote, protect and advance women's rights in social, economic, political and cultural fields, with special emphasis on women's participation in conflict resolution and decision-making at all public and private levels.

\subsubsection{Strategies used by women regarding promoting the community peace and stability}

The FGD participants were asked what strategies the women in Alamata Town used in promoting the community peace and stability. Hence, most of the participants said strategies and tactics are key operational elements that translate the general philosophy of enhancing the community peace and stability into actions and behaviors. The FGD participants' summarized the strategies as follows:

Geographic Focus: The FGD participants mentioned that by involving a police in the town on a longer term basis, resident will develop trust in providing information to the police officer. To execute this idea, 1 police officer and 10 women were assigned in each kebeles of the town. All the town women are subdivided in to several kebeles for the purpose of promoting the community peace and stability, which can help to tailor problem solving efforts to the communities' unique problems. Thus, the women in collaboration with the town police , most of whom are assigned for more than two years in specific areas, are responsible for small geographic areas, i.e.,kebeles and ketenas, so that they can able to know residents, social problems and their concerns.

Crime Prevention Focus: women have based their strategies on the 'broken windows' hypothesis of enhancing the community peace and security through eliminating disorder behavior. To prevent the occurrence of conflict and crime problems rather than to react after the incident, the capacity of the women to prevent such problems has been strengthened by encouraging them to have civilian patrols. In this regard, women as community members are becoming "the first line of defense in the fight against conflict and crime.

The Use of Foot Patrol: It is also the case that the deployment of on foot women in the town has continued. Foot patrol, popular tactic of enhancing the community peace and security, may put women in closer contact with citizen and reduce opportunities for disorder in the town.

Positive Interaction with the Community: it is argued that women should take every opportunity to engage in positive interaction with all members of the community. In doing so, most women have been attending 
neighborhood meetings and involved indigenous community associations like Eder and Equb and mahber in the town.

Emphasis on Problem-Solving: Although most women have received little training, they have been using SARA problem solving model which involves scanning, analyzing, response and assessment crime related problems. However, problem analysis and response assessment were not routinely happening.

In addition, the FGD participants added concerning the strategies used by women regarding promoting the community peace and stability through making the women more accessible to the town people; training, assigning and empowering of women on the beat, then evaluating their performance; educating the community to uplift their concept of and responsibility in crime prevention activities.

4.2.4. The women- police relationship in keeping peace and stability of the local community The FGD participants were asked to rate the levels of women- police relationship in keeping peace and stability of the local communities. Accordingly, 70\% of the FGD participants replied that the women- police relationship in keeping peace and stability of the local communities was good. According to them, the possible reasons given for the good women-police relationship were as follows:

$\checkmark$ The women have willingness and interest to participate in their own security matters;

$\checkmark$ Women give response to police calls;

$\checkmark$ The eyes and ears of the police;

$\checkmark$ Commenting and correcting the residents misconduct;

$\checkmark$ Women provide crime-related information to the police; and

$\checkmark$ Women do not perceived the police as arrogant and brutal rather consider as potential partners in solving conflicts

Moreover, the researcher attempted to assess the existing women- police relations. Accordingly, the researcher observed that the women of the town were willing to participate in community forums and hand over criminals to police by providing necessary information.

However, $30 \%$ of the research participants stated the women-police relationship as poor. They mentioned the following possible reasons for the poor or weak relationship as follows:

- A legacy of illegitimacy and distrust emanating from past police extra-legal, brutal and terrible memories as well as malpractices still exists between the police and the women. Hence, the communities were substantially unwilling to voluntarily assist the police;

- Lack of knowledge and understanding of women-police relation in keeping peace and stability of the community

- The police always use force and apprehend citizens without reason;

- The police paid little attention to the inclusion of women in peace and stability matters.

\subsubsection{Factors that hinder the participation of women in conflict resolution in the study area}

According to the FGD participants, there are various factors influencing participation of women in conflict resolution. For them, these factors include: social factors like male domination and traditional beliefs and religion of the society, skills factors like lack of knowledge and skills needed for conflict resolution, economic factors because of poverty and economic inequality which hinders women's involvement in conflict resolution activities. In support of this idea, Ekvall (2015) remarked that women have been confined and prevented from participating in public life, in conformity with dictates of tradition, culture and religion. Moreover, Gibing (2011), stated that the lack of adequate, targeted funding for conflict resolution efforts is also a major economic barrier that has limited the participation of women at national and local levels.

The FGD participants identified that lack of resources among women seriously undermines their conflict resolution efforts. Women's desire to participate in conflict resolution activities is bedecked by slow entrenchment and lack of full implementation due to partly discriminatory practices in traditions, cultures and policies. They added that lack of education and access to information negatively affected women participation in sustainable conflict resolution issues and peace building process. Cultural practices such as women's role of bearing children; gender insensitive approaches to conflict resolution, association of women with domestic spheres among others negated women involvement in sustainable conflict resolution initiatives in the study area.

\subsubsection{What can be done to enhance women's involvement in conflict resolution process?}

The FGD participants strongly argued that above all the obstacles to the involvement of women in conflict resolution process. The respondents concluded that as seen in the town conflict resolution process, provisions in peace accords fail to make reference to women as actors and agents of change for peace. The language of the agreement was weak, and deprived women of a political space where they could contribute to the building of peace as recognized partners, not only as mothers or dependents on a male relative. Women are generally defined as members of vulnerable groups, together with the elderly and the handicapped, as part of the category "women-and-children". They are first and foremost considered as hopeless victims unable to take charge of the lives, and this approach deprives them of the agency as responsible.

They suggest the following solutions to enhance women's involvement in conflict resolution process. 
Creating political strength and political vision: Women suffer from "political illiteracy". They lack an ideological framework that could give teeth to a strong position adopted by a collective women's. Conflict resolution as a political activity and therefore requires political strategy for engagement.

Sharing experience, exposure and skills in negotiation, advocacy and lobbying techniques: Women have always been kept secluded from the political arena and sphere of decision-making; therefore, in many situations they are unable to participate.

Promoting women's political platform: Without a political platform, women are on the margins of action and lack confidence in participating in the peace building and conflict resolution process.

Creating visibility: Women's conflict-resolution activities are confined to the informal sector, very often at the periphery of official conflict resolution. In addition, even if women contribute to the promotion of peace, they are not invited to participate in formal negotiations.

Allocating resources (material and financial): Most of the time women's groups lack the means to back up their actions. In some instances, they are unable to get across to the media network to enhance their peace campaign because they do not have a budget for multi-dimensional activities. Further, they are not part of main fund raising channels and networks. They work on a voluntary basis at the grassroots levels, pooling their own resources together to get an office, desk, and phone line.

Encouraging sustainability in political participation: Representation does not necessarily mean meaningful and recognized participation that has an impact on substantial inputs in peace agreement. In addition, once a peace process is over, women often return to more traditional activities, losing their gains and public presence. These losses make it very difficult for women to return to the public stage later when resolution begins.

\section{Chapter Five: Conclusion and Recommendations}

\subsection{Conclusion}

This study examines the role of women in conflict resolution in the case of Alamata Town. The women have played their role in crime resolution activities, though not enough, voluntary and have attempted to maintain their own peace and stability. The level of women participation in conflict resolution in the town rated as high as numerous efforts were made by women. However, $10 \%$ of the FGD participants strongly argued that women are excluded from principal roles in conflict resolution in the town.

The study has identified several strategies used by women regarding promoting the community peace and stability mainly geographic focus, crime prevention focus, the use of foot patrol, positive interaction with the community, emphasis on problem-solving, training, assigning and empowering of women on the beat, then evaluating their performance, and educating the community to uplift their concept of and responsibility in crime prevention activities.

The study revealed that lack of resources among women seriously undermines their conflict resolution efforts. Women's desire to participate in conflict resolution activities is bedecked by slow entrenchment and lack of full implementation due to partly discriminatory practices in traditions, cultures and policies. They added that lack of education and access to information negatively affected women participation in sustainable conflict resolution issues and peace building process. Cultural practices such as women's role of bearing children; gender insensitive approaches to conflict resolution, association of women with domestic spheres among others negated women involvement in sustainable conflict resolution initiatives in the study area.

The study has shown that $70 \%$ of the FGD participants replied that the women- police relationship in keeping peace and stability of the local communities was good. However, $30 \%$ of the research participants stated the women-police relationship as poor.

Lastly, the study suggests the following solutions to enhance women's involvement in peace building and conflict resolution process. These includes: creating political strength and political vision; sharing experience, exposure and skills in negotiation, advocacy and lobbying techniques ; promoting women's political platform; creating visibility; allocating resources (material and financial); and encouraging sustainability in political participation.

\subsection{Recommendations}

The study recommends that social and economic development should be encouraged to secure the participation of women as equal partners with men in conflict resolution activities. Literacy programs should also be offered to encourage women's participation in conflict resolution issues. Women's organizations, networks and civil societies should promote strong and sustainable peace networks at the town level. Women organizations and civil society must develop the skills and technical expertise to solve conflicts successfully and ensure that women's voices are not only heard but also incorporated into peace programs and policies that mandate gender mainstreaming within the conflict resolution matters in the society.

For Alamata Town women to be effective in the conflict resolution role, they must organize themselves, strive for institutional, political and legal representation, and create solidarity and support through zonal and 
regional networks.

The Town administrator and the government have to work together to strength the women- police relationship and help women to form good integration with stakeholders in order to resolve conflicts as well as to keep peace and stability of the local communities.

There is a need to overcome the obstacles that hinder women from participating in conflict resolution process. Therefore, there is a need to have a discussion with women's groups and movements that would convey more details on how conflict or waging conflict affects people on the ground. There is also a need to provide information about the concerns that women have, thus empowering women as major and serious actors who should be included in conflict resolution and peace building.

\section{Acknowledgment}

I am grateful to all of those with whom I have had the pleasure to work in writing this article.

I thank you!!!

\section{References}

Anderlini, S.N., .2007. Women Building Peace: Why They Do It, Why It Matters, Boulder, USA: Lynne Rienner Publishers, Inc.

Becker.2003. What Women Do in Wartime: Gender and Conflicts in Africa? London: Zed Books.

Brewing. 2012. Issue Paper: Women, Gender and Peace Building: Do Contributions add up? Collaborative Learning Projects.

Boutros-Ghali, B., .2002. An Agenda for Peace: Preventive Diplomacy, Peacemaking and Peace-Keeping', available at: http://www.un.org/Docs/SG/agpeace.html accessed on 10/05/12

Butler, J. 2009. Gender Trouble: Feminism and the Subversion of Identity. New York: Routledge.

Crawford, A. 2008. Crime Prevention and Community Safety: Policies, Politics and Practices. New York: Longman.

Dempsey, J.S. 2010. Introduction to Policing (2nd ed.). Belmont, CA: Wadsworth.

El-Bushra, Judy. 2012. Gender in peace building, Taking Stock. London: International Alert.

Galtung, J. 2007. Peace by Peaceful Means: Peace and Conflict, Development and Civilization. Oslo: PRIO.

GAPS. 2010. UNSCR 1325: The Participation Promise. United Kingdom: GAPS UK.

Grenier, Y., \& Daudelim J. 1995. Foreign Assistance and the Market-place of Peacemaking: Lesson from El Salvador. International peacekeeping 2(3), 350-364.

Habtamu Wondimu .2008. Handbook of Peace and Human Rights Education in Ethiopia Organization for Social Science Research in Eastern and Southern Africa (OSSREA), Addis Ababa, Ethiopia.

McCarthy Mary K. 2011. A woman's Participation in Peace Building: A Missing Piece of thePuzzle? University of Pennsylvania.

Mitchell, C., \& Banks, M. 2009. Handbook of Conflict Resolution: The Analytical Problem-Solving Approach. London: Pinter.

Miller, C.A., \& King, M.E. 2003. A Glossary of Terms and Concepts in Peace and Conflict Studies. Addis Abba, Ethiopia: University for Peace Africa Program.

Mpangala, G.P. 2004. Origin of Political Conflict and Peace Building in the Great Lakes Region. Paper Presented at the Symposium "Ramifications of Instability in the Great Lakes Zones, organized by the Command and Staff College, Arusha, Burundi.

Munro Jean. 2000. Gender and Peace Building. Ottawa: Peace Building and Reconstruction Program Initiative.

Murray, E. 2011. Gender, Conflict, and peace building: State of the Field and Lessons Learned from USIP Grant making. Washington DC: USIP.

Resolution 1325. 2000. United Nation Security Council Resolution.

Simonov, D. 2010. Interactive Expert Panel: Commemorating 30 Years of CEDAW Converging Tracks: The Convention on the Elimination of all Forms of Discrimination against Women and the Platform for Action and the Way Forward for Gender Equality. New York.

Wilson Center. 2013. The Peace Process in Colombia. Washington DC: The Wilson Center. 